\title{
Implementation of Service Learning into Engineering Design
}

\author{
Peter Doiron, Brady Gallant and Libby Osgood \\ pedoiron@upei.ca,kbgallant@upei.ca and eosgood@upei.ca
}

\begin{abstract}
This paper will discuss themes related to the implementation of the engineering design process by two second-year engineering students while working in an international setting on a service learning project. In February 2015, the authors of this paper designed, tested, and implemented a novel wheelchair attachment to improve the mobility of persons with disabilities in Kenya. This project was carried out in its entirety during a period of 2 weeks, while staying in the small village of Mikinduri, located in Kenya's Eastern Province. The scope of this paper will include benefits of implementing such projects into engineering design curriculum, along with recommendations based on the authors' experiences. Topics such as CEAB Graduate Attributes covered, material availability, and communication barriers will be compared and contrasted between standard and service learning design projects.
\end{abstract}

\section{INTRODUCTION}

The purpose of this paper is to provide insight on how service learning projects can be implemented into design courses, and how they benefit students. The authors of this paper completed a second-year design project with a service learning element in an international setting, which serves as the basis for this paper. Standard design projects offer students the ability to apply knowledge gained in technical courses to solve a real-world problem. This was also the case in the project which this paper will focus on, however additional insights into sustainability, ethics, and equity were gained.

The project referred to in this paper was completed from September 2014 to April 2015. A design was developed in the first semester of the academic year, and the students travelled to Kenya in February 2015 to refine the project and proceed with implementation.

\section{BACKGROUND}

This section will discuss topics which were discovered upon review of existing literature in the areas of service-learning, the engineering design process, and autoethnography. The literature will be compared to the experiences of the authors in a reflection on whether the supposed outcomes of service learning were achieved and if a typical design process was implemented.

\subsection{Service Learning}

Service learning is a topic which engineering curricula benefit from greatly. Engineering as a profession has the ability to impact communities of all forms, and so service learning is an exceptional method to expose students to these opportunities early in their careers. According to the National and Community Act of 1990 [1]:

"The term "service-learning" means a method-

(A) under which students or participants learn and develop through active participation in thoughtfully organized service that-

(i) is conducted in and meets the needs of a community;

(ii) is coordinated with an elementary school, secondary school, institution of higher education, or community service program, and with the community; and

(iii) helps foster civic responsibility; and

(B) that-

(i) is integrated into and enhances the academic curriculum of the students, or the educational components of the community service program in which the participants are enrolled; and

(ii) provides structured time for the students or participants to reflect on the service experience.

This definition is of particular relevance to the project which this paper focuses on. As will be discussed in further sections, the project was completed with the help of students at Athwana Youth Polytechnic, a local technical school, thereby fulfilling definition (A)(ii). The project also greatly enhanced academic curriculum of the course in which the project was completed, and ample time was available for 
reflection and further work upon return to Canada. Finally, the project benefitted and fulfilled the needs of a Kenyan family, providing a sense of duty and fulfillment to the authors.

\subsection{Engineering Design Process}

The design process is vital to any design project. Due to the unusual constraints on the project presented in this paper, a comparison between a standard design process and the process which was followed was created. Lima and Oakes [2] break the design process into 7 phases, as shown below:

1. Problem Identification

2. Specification development/planning

3. Conceptual design

4. Detailed design

5. Production

6. Service and maintenance

7. Redesign or retirement and disposal

The design process which was followed through the duration of this project did resemble Lima and Oakes' process. However, due to the unique layout of the year, with the trip being in the middle of the second semester, some steps from this design process were repeated. The majority of the first semester was spent trying to completely understand the problem and create a design to solve it. This would represent steps 1-3. Once arriving in Kenya, speaking to the locals was done to understand the specific issues they have and then creating working solution was fabricated and given to them. This would represent steps 1-5. With the month remaining after returning from Kenya, improvements were made to the Kenya model and then an iterated 3D model was printed. This would represent steps 4-5. A graphic showing the design process for this project is shown in Table 1.

Table 1: Design process steps throughout year

\begin{tabular}{|c|c|c|c|}
\hline Steps & $\begin{array}{c}\text { First } \\
\text { Semester }\end{array}$ & $\begin{array}{c}\text { Kenya } \\
\text { Trip }\end{array}$ & $\begin{array}{c}\text { After } \\
\text { Kenya }\end{array}$ \\
\hline 1 & & & \\
\hline 2 & & & \\
\hline 3 & & & \\
\hline 4 & & & \\
\hline 5 & & & \\
\hline
\end{tabular}

\subsection{Autoethnography}

Autoethnography, a qualitative research approach, refers to the question "How does my own experience of this culture connect with and offer insights about this culture, situation, event, and/or way of life?" [3] This topic, however, was reflected upon with regards to how taking part in this design project resulted in knowledge gain and additional insights about engineering design that would not have occurred had a standard design project been completed. Standard design projects at the University of Prince Edward Island (UPEI) involve regular meetings between the students and their client, along with frequent correspondence through email and over the phone. The majority of the work however is completed at UPEI. This project differed from those in that the large majority of the project was completed while working in the setting where the device was to be used, and in close proximity to the client. This experience provided the authors with a greater understanding of the importance of keeping the client and their needs at the forefront of all steps of the design process. This paper will use the framework of authoethnography.

\section{DESIGN OVERVIEW}

Mikinduri Children of Hope (MCOH) is an organization dedicated to helping improve the quality of life for the people of Mikinduri and nearby villages in Kenya. Representing $\mathrm{MCOH}$ as the clients for this project were Mr. Ted Grant and Dr. Ed Harrison. The goal for this project was to design a simple wheelchair attachment that will aid persons with disabilities (PWD) to navigate the rough terrain in Giithu, a small community in the mountains of eastern Kenya. While in Kenya, residents of nearby areas gave input on the design and a local polytechnic helped with the construction of the design. Throughout the year the design changed significantly, shown in Figure 1.

The design from the first semester proved to be a challenge because it was not known what would benefit the end user as well as the feasibility in manufacturing and implementing the design. Once arriving to Kenya, talking to residents narrowed down the problem to maneuverability around the area, hence the handle design was chosen. The handles reduced the amount of effort required to push a person in a wheelchair up steep hills, while improving control on downward slopes by means of a hand brake system.

CEEA16; Paper 97

Dalhousie University; June 19 - 22, 2016 


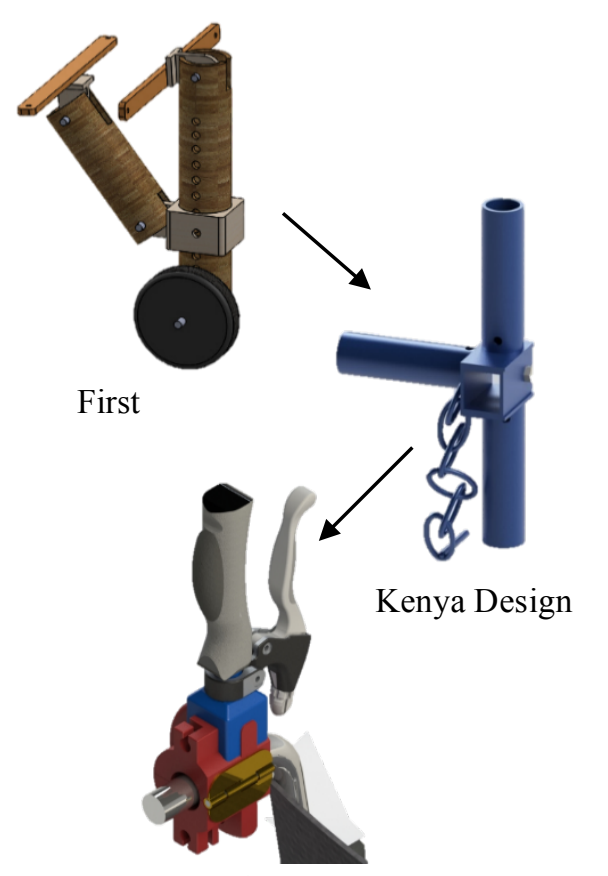

Iterated

Figure 1: Evolution of design

The design was iterated upon returning to Canada, but was $3 \mathrm{D}$ printed due to time constraints.

\section{HERE VERSUS THERE}

\subsection{Graduate Attributes}

The CEAB Graduate Attributes are fundamentally important for measuring the success of engineering programs across Canada. There are 12 Graduate Attributes (GA) [4], listed in Appendix A. Most design projects at UPEI cover a number of the GAs, however the service learning component of the project shifted the GAs which were heavily focused on. Table 2 shows the GAs which are focused on in standard projects compared to the project in question.

Because this project allowed for constant interaction with the end user and their community, the impact that the project would have on residents was highlighted. It served as a useful learning tool for the many ways methods through which engineering can have an impact on society.

Due to the limited amount of resources, the sustainability of the device was of great importance. Compared to standard design projects in which material is often wasted without any considerations for sustainability, material was limited in availability, and so very little material was wasted. This also reduced the cost of the device, increasing the feasibility for mass production of the device.

While project management is stressed in all design projects, it became paramount during the 2 weeks spent working in Kenya. With such a short amount of time to complete the design, there was little room for error. Detailed build and test plans were crucial to ensuring as few mistakes as possible were made, as errors could have resulted in the device not being completed in time.

As the majority of the project was completed in a third world country, it was evident that many of the residents were not afforded the same opportunities which are often taken for granted in Canada. This allowed for a reflection by the students on GA 10 , Ethics and Equity, and what role these concepts play when designing.

\subsection{Material Availability}

A large challenge which came as a result of constructing the device in Kenya was material availability. In Canada, a large number of materials are readily available and can usually be acquired within a very short time frame. As a result, the availability of a material required by the design is not an issue. While in Kenya, the lack of material availability proved to be a difficulty. Simply acquiring metal tubing to construct the device with involved a half-day trip to a larger town where it could be purchased.

Table 2: Comparison of emphasized GAs

\begin{tabular}{|c|c|}
\hline Standard Projects & $\begin{array}{l}\text { Global On-Site Service } \\
\text { Learning Project }\end{array}$ \\
\hline Problem Analysis & Problem Analysis \\
\hline Investigation & Investigation \\
\hline Design & Design \\
\hline $\begin{array}{l}\text { Use of Engineering } \\
\text { Tools }\end{array}$ & Use of Engineering Tools \\
\hline & $\begin{array}{l}\text { Impact of Engineering on } \\
\text { Society and Environment } \\
\text { Sustainability, } \\
\text { Economics and Project } \\
\text { Management } \\
\text { Ethics and Equity }\end{array}$ \\
\hline
\end{tabular}


As previously mentioned, project management was extremely important to ensure that all materials which would be necessary were purchased in a single trip, to prevent additional lost time in travel.

While it was expected that material availability and selection would be an issue, the degree to which materials were limited was higher than anticipated. While discussing this issue before the trip, it was expected that a common metal such as steel could be obtained easily within the village, as opposed to the long trip that was required in reality.

While obtaining the proper materials was a challenge, the limited material selection and manufacturing abilities proved to be an advantage. The few available materials provided early guidance for the design. In Canada, designs can often become more complicated than necessary as the possibilities of what can be manufactured have become nearly infinite. In Kenya however, the design had to be simple out of necessity, as manufacturing techniques were very basic. This reduced the number of complex parts, thus reducing the chances for failure.

\subsection{Language/Terminology}

Communication problems are always possible when travelling to a foreign country. These issues became especially prevalent while building the device with the local students, as many technical terms were being used. Occasionally, two parties used a different word to describe the same object, creating confusion. These slight challenges meant that instructions had to be clearly communicated, and checks had to be performed to ensure that all parties understood what had been communicated. To help remedy these issues, the students were accompanied to the Polytechnic each day by a local resident who acted as a translator. While many of the students and instructors spoke English, the aforementioned issues necessitated the translator.

\section{TEACHING RECOMMENDATIONS}

This section is split up into three sub-sections: Before trip, during trip and after trip. Each sub-section will discuss how to implement and optimize similar projects into engineering curriculum.

\subsection{Before Trip}

There are many factors that facilitate a successful and educational trip, the first one being sufficient time for the students to prepare before the trip. This is essential for maximizing the quality of their trip. At least one semester should be given to the students, so they will have time to research and develop different ideas with their client. The client plays a pivotal role throughout the project, giving advice and expertise to the students when they need it. Having the client available as much as possible in the very beginning can help inform the students of the area they will be working in. This includes geographical area, what is available in the area and what is culturally acceptable in the area. The students will heavily rely on the client at the beginning for their knowledge in narrowing down a potentially broad problem statement.

With this project, the problem statement was broad and at the start, little was known other than improving the accessibility of persons with disabilities in Kenya. The group narrowed down the scope to focus on wheelchair attachments, but even with the guidance of their client, creating a feasible design was a challenge. Allowing the students to develop their own ideas based on their problem statement is a skill that all engineering students need to practice, but to save time, it is crucial that the client and the professor help steer the students back in the right direction when they are completely off track. With the appropriate amount of help from the client and professors, the students should aim to have complete a $3 \mathrm{D}$ model of the potential design before the trip.

\subsection{During Trip}

It is imperative that the students that are traveling do not waste their time on the trip. Before leaving, they should construct a work breakdown structure (WBS) of how each day they are on the trip will be laid out. This can either be done using software such as Open Project or Excel. The group members for this project used Excel to organize their trip because of the short time frame as well as the short time intervals throughout the trip. This WBS is shown in Figure 2 on the next page. Following this schedule is crucial in finishing a project in a short period of time.

This next point can vary from project to project, but if it is possible to have the client attend the trip to help give input to the students, it could benefit them. This depends on how much the client actually helped previous to the trip, but if the client could at least be available to Skype to give guidance to the students, it might help them. In this project, a professor who has been to Kenya multiple times was more than enough help when the students were stuck with a problem, so a client was not completely necessary for them.

CEEA16; Paper 97

Dalhousie University; June 19 - 22, 2016 


\begin{tabular}{|c|c|c|c|c|c|c|c|}
\hline & Sunday & Monday & Tuesday & Wednesday & Thursday & Friday & Saturday \\
\hline & & & & & & -Land in Kenya & -Travel \\
\hline Week 1 & $\begin{array}{l}- \text { Check out the } \\
\text { village }\end{array}$ & $\begin{array}{l}\text {-Talk to locals } \\
\text {-Ideation }\end{array}$ & $\begin{array}{l}\text {-Preliminary } \\
\text { Design } \\
\text {-CAD }\end{array}$ & $\begin{array}{l}\text {-Detailed Design } \\
\text {-Requirements } \\
\text { and Verification } \\
\text { Matrix }\end{array}$ & $\begin{array}{l}\text {-Cost analysis and } \\
\text { material } \\
\text { sourcing/acquisiti } \\
\text { on }\end{array}$ & $\begin{array}{l}\text {-Build } \\
\text { procedure }\end{array}$ & -Build \\
\hline Week 2 & -Small planning & -Building & -Test plan & $\begin{array}{ll}\text {-Testing and } \\
\text { building }\end{array}$ & -Iteration & -Iteration & $\begin{array}{ll}\begin{array}{l}\text { Leave for } \\
\text { home }\end{array} & \\
\end{array}$ \\
\hline
\end{tabular}

Figure 2: WBS of trip to Kenya

It is obvious from looking at the first Semester and the Kenya designs, the focus of the design changed once arriving in Kenya. This is because of talking to locals in multiple communities around the area. They described the issues which existed and suggested different solutions for them. Making time to have conversations with residents of the town that is being traveled to, is vital to having a successful project. They know what the issues are because they either see them or live through them every day. Something that this group did that allowed for a greater number of interviews in a shorter period of time was to get someone in the community to organize the interviews before the day that they happen. This saves time and allows the interviewees to think of meaningful answers. Again, before leaving on the trip, having as many things planned as possible will benefit the students as there are a lot of unforeseen circumstances that occur while on the trip. These events take up precious time.

Another great way for the students to learn is to write a reflection every night, after work, of what happened, what worked well, what did not work well and how it could be improved, what is being worked on tomorrow and if they on schedule. This will keep the students thinking about the project and it will also improve their logbook keeping skills, which are essential for any engineer.

\subsection{After Trip}

This section depends on when the students get back during the semester and what they are expected to have submitted. Returning from Kenya, the group had only a month to build something for the end of the year expo. Based on tests and feedback from the end user, there was some iterations that were done. Depending on time constraints, having the students reflect on their design and possibly make alterations to the $3 \mathrm{D}$ computer model and potentially $3 \mathrm{D}$ print a working prototype is possible.

Following up with the client is also a wise idea that the students should do to get their input on the final design. The client can help them with further iterations as well. Following up with the end user is also a great way of figuring out possible changes to the design that were not seen right when it was given to them. These suggestions all depend on what the students are expected to complete as well as how invested they are in the project after the trip.

\section{CONCLUSION}

Overall, this trip provided the authors with a greater understanding of how engineering can be used to dramatically impact the lives of ordinary people. It was also an experience which revealed the importance of helping the less fortunate so that the global society may become stronger.

Working on this project while on the ground in Kenya provided a significantly greater understanding of the problem. As was shown, the design changed drastically upon arrival in Kenya, being modified to better suit the end user's needs.

Although the trip was difficult to organize and often stressful to the time constraint, the end product was significantly better than if the same project had been completed without travelling to Kenya.

Finally, the authors recommend integrating service learning and travel components into engineering design curriculum, as they increase the number of Graduate Attributes the course covers, and enrich the students' experience. 


\section{REFERENCES}

[1] Corporation for National and Community Service, "The National and Community Service Act of 1990," 1990.

[2] M. Lima and W. Oakes, Service-Learning: Engineering in Your Community, New York: Oxford University Press, 2006.

[3] M. Q. Patton, Qualitative Research and Evaluation Methods, 3rd Edition, Thousand Oaks, CA: Sage Publications, 2001.

[4] Engineers Canada , "2015 Accreditation Criteria and Procedures," Engineers Canada, 2015.

\section{APPENDIX A: CEAB GRADUATE ATTRIBUTES}

The CEAB Graduate Attributes are listed below:

1. Problem analysis

2. Investigation

3. Design

4. Use of engineering tools

5. Individual and team work

6. Communication skills

7. Professionalism

8. Impact of engineering on society and the environment

9. Ethics and equity

10. Economics and project management

11. Life-long learning 